\title{
Association of APOA5 rs662799 and rs3135506 polymorphisms with arterial hypertension in Moroccan patients
}

\author{
Sanaa Ouatou ${ }^{1}$, Maria Ajjemami ${ }^{1}$, Hicham Charoute ${ }^{1}$, Hajar Sefri ${ }^{1}$, Noreddine Ghalim² ${ }^{2}$, Houria Rhaissi ${ }^{3}$,
} Houda Benrahma', Abdelhamid Barakat ${ }^{1 *+}$ and Hassan Rouba ${ }^{1+}$

\begin{abstract}
Background: The goal of the study is to investigate the association between the APOA5 polymorphisms and haplotypes with Arterial Hypertension (AHT) in Moroccan patients.

Methods: The study was performed in 283 subjects, 149 patients with AHT and 134 controls. All subjects were genotyped for the APOA5 -1131 T > C (rs662799), 56C > G (rs3135506) and c.553G > T (rs2075291) polymorphisms.

Results: There was a strong association between $-1131 \mathrm{~T}>\mathrm{C}$ and $56 \mathrm{C}>\mathrm{G}$ polymorphisms with AHT. The -1131 $T>C$ and $56 C>G$ polymorphisms were significantly associated with increased systolic blood pressure (SBP) and triglycerides (TG) levels. There were 4 haplotypes with a frequency higher than $5 \%$, constructed from APOA5 polymorphisms, with the following order: $-1131 \mathrm{~T}>\mathrm{C}, 56 \mathrm{C}>\mathrm{G}$ and c.553G > T. Haplotype H1 (TCG) was associated with decreased risk of $A H T$, whereas the haplotypes $\mathrm{H}_{2}$ (CCG) and $\mathrm{H} 4$ (CGG) were significantly associated with an increased risk of AHT. Carriers of $\mathrm{H} 1$ haplotype had a lower SBP and DBP and TG. In contrast, significant elevated SBP, DBP and TG were found in H4 haplotypes carriers.

Conclusions: Our data demonstrate for the first time that several common SNPs in the APOA5 gene and their haplotypes are closely associated with modifications of blood pressure and serum lipid parameters in the AHT patient.
\end{abstract}

Keywords: APOA5 gene, Polymorphisms, Haplotypes, Arterial hypertension, Morocco

\section{Background}

Arterial hypertension (AHT) is one of major public health problem in the world, it will affect more than 1.56 billion adults worldwide in 2025 [1]. Hypertensive individuals have higher risk to develop coronary artery disease (CAD), cerebrovascular disease and heart failure than normotensive persons [2]. Effectively, The American Heart Association reported that the hypertension and dyslipidemia are one of the main risk factor for development of CAD $[3,4]$. AHT is a polygenic and multifactorial disease resulting from combination between genetics and environment factors.

\footnotetext{
* Correspondence: hamid.barakat@pasteur.ma

${ }^{\dagger}$ Equal contributors

'Laboratoire de Génétique Moléculaire et Humaine, Département de Recherche Scientifique, Institut Pasteur du Maroc, 1, Place Louis Pasteur, 20360 Casablanca, Morocco

Full list of author information is available at the end of the article
}

Apolipoprotein A5 (APOA5) gene, related to the metabolism of triglycerides in several different ethnic groups [5]. It locates on chromosome 11q23, and forms a cluster with $A P O A 4, A P O C 3$ and $A P O A 1$ genes. In mice, invalidation and over-expression of $A P O A 5$ result in increased and decreased triglyceride levels, respectively by controlling the activity of lipoprotein lipase (LPL) [1]. APOA5 codes for a protein of 366 amino acids which function is to modulate intracellular hepatic VLDL synthesis. The most studied APOA5 SNP was the $56 \mathrm{C}>\mathrm{G}$ (S19W, rs 3135506), because it is associated with increased TG levels [6,7]. Indeed, numerous studies in different ethnic populations have shown significant associations between two minor APOA5 haplotypes, APOA $5 * 2$ and APOA $5 * 3$, and elevated plasma triglyceride levels [5,8]. It is estimated that $53 \%$ of Hispanics, $35 \%$ of African-Americans, and 24\% of Caucasians carry 
at least one of these two haplotypes [6], thus suggesting that these haplotypes are common risk factors for atherosclerosis.

In this study, we investigated the association of the APOA5 polymorphisms and haplotypes with AHT in Moroccan patients.

\section{Methods \\ Study population}

Our study concerned 283 Moroccan adult volunteers (177 women and 106 men), 149 patients diagnosed as hypertensive by medical corps (systolic blood pressure $>140 \mathrm{mmHg}$ and/or diastolic blood pressure $>90 \mathrm{mmHg}$, and treated by antihypertensive drugs) and 134 controls (non smoking healthy persons with normal lipid levels and normal blood pressure, and women were non-pregnant and non-breastfeeding). At enrolment in the Medical Biology Center of Pasteur Institute of Morocco in Casablanca, they completed a health and lifestyle questionnaire including social demographics characteristics, medical history, medications intake and lifestyle factors as tobacco consumption, physical activity and alcohol intake. The clinical examination consisted of questionnaire and a physical examination: age, gender, geographical origin, family history, body mass index, smoking habits, the presence of hypertension, diabetes, hypercholesterolemia or cocaine use, and levels of physical activity and alcohol consumption performed at the Pasteur Institute in Casablanca. All subjects (patients and controls groups) included in this study were from different geographic and ethnic backgrounds from Morocco.

\section{Ethics statement}

We obtained written informed consent from each subject and the research protocol was approved by the committee on research ethics of Pasteur Institute of Morocco.

\section{Blood pressure measurement}

Arterial pressure was measured by the auscultatory method using a stethoscope and a sphygmomanometer. All measurements were performed by nurse in the Medical Biology Center of Pasteur Institute of Morocco in Casablanca.

\section{Biochemical measurements}

The blood was collected in two tubes (EDTA and dry tubes) from subject after 12 hours overnight fasting. The samples were centrifuged and stored at $-20^{\circ} \mathrm{C}$. Glycemia, total cholesterol (TC), Triglycerides (TG) and HighDensity Lipoprotein Cholesterol (HDL-C) levels were determined using the VITROS (5.1 FS Chemistery System). Low-density Lipoprotein Cholesterol (LDL-C) level was calculated according to the Friedwald's formula. All biochemical measurements were performed in the Biochemistry Laboratory of the Medical Biology Center in Pasteur Institute of Morocco.

\section{Molecular analysis: genotyping APOA5 polymorphisms}

Genomic DNA was extracted from peripheral leukocytes by standard methods including proteinase $\mathrm{K}$ digestion, followed by phenol-chloroform extraction and ethanol precipitation. The $56 \mathrm{C}>\mathrm{G}$ and $-1131 \mathrm{~T}>\mathrm{C}$ polymorphisms were determined by PCR-RFLP analysis. All PCR were performed in a Biometra thermal cycler, using Taq Polymerase (Bioline). A fragment of $157 \mathrm{bp}$ including the $56 \mathrm{C}>\mathrm{G}$ polymorphism was amplified using two oligonucleotides, forward: 5'- GGC TCT TCT TTC AGG TGG GTCBTCCG -3'reverse: 5' - GCC TTT CCG TGC CTG GGT GGT - $3^{\prime}$ [9]. The PCR conditions were an initial denaturing at $96^{\circ} \mathrm{C}$ for $5 \mathrm{~min}$, followed by $30 \mathrm{cy}$ cles of $96^{\circ} \mathrm{C}$ for $30 \mathrm{~s}, 64^{\circ} \mathrm{C}$ for $30 \mathrm{~s}, 72^{\circ} \mathrm{C}$ for $45 \mathrm{~s}$, and a final extension of $72^{\circ} \mathrm{C}$ for $10 \mathrm{~min}$. The PCR products were digested for 2 hours at $65^{\circ} \mathrm{C}$ with TaqI restriction enzyme: the C56 allele presents a TaqI restriction site which is suppressed in the $56 \mathrm{G}$ allele. Genotyping for $-1131 \mathrm{~T}>\mathrm{C}$ was performed with the following primers: Forward: 5' - CCC CAG GAA CTG GAG CGA AA TT-3', reverse 5'- TTC AAG CAG AGG GAA GCC TGTA-3'. The PCR conditions were an initial denaturing at $96^{\circ} \mathrm{C}$ for $5 \mathrm{~min}$, followed by 32 cycles of $95^{\circ} \mathrm{C}$ for $30 \mathrm{~s}$, $55^{\circ} \mathrm{C}$ for $30 \mathrm{~s}, 72^{\circ} \mathrm{C}$ for $30 \mathrm{~s}$, and a final extension of $72^{\circ} \mathrm{C}$ for $10 \mathrm{~min}$. The PCR products were digested with Mse I. A fragment of $138 \mathrm{bp}$ of the c.553G $>\mathrm{T}$ polymorphism was amplified using two oligonucleotides. The PCR conditions were an initial denaturing at $96^{\circ} \mathrm{C}$ for $5 \mathrm{~min}$, followed by 35 cycles of $96^{\circ} \mathrm{C}$ for $30 \mathrm{~s}, 63^{\circ} \mathrm{C}$ for $30 \mathrm{~s}, 72^{\circ} \mathrm{C}$ for $45 \mathrm{~s}$, and a final extension of $72^{\circ} \mathrm{C}$ for $10 \mathrm{~min}$. The PCR products were digested for overnight at $37^{\circ} \mathrm{C}$ with HaeIII restriction enzyme. All molecular analyses were performed in the Human Genetic Laboratory in Pasteur Institute of Morocco.

\section{Statistical analysis}

Clinical and biochemical data were expressed as means \pm standard deviation (SD). Student's t test was applied for comparison of quantitative traits that follow a normal distribution. Otherwise, we used Manne-Whitney test. Chi-square test and logistic regression analysis were performed to test the association between Arterial Hypertension and APOA5 genotypes and haplotypes. Logistic regression analysis was adjusted by age and gender. A P value of less than 0.05 was considered statistically significant. All statistical analyses were performed using STATA software, version 11.0. The P-values were corrected with the Bonferroni correction by multiplying with the number of comparisons. For haplotype frequencies estimation and comparison we used the PLINK software, version 1.07. All haplotypes with frequencies less than $5 \%$ were ignored in 
analysis. Linkage disequilibrium between each pair of APOA5 polymorphisms was estimated using Haploview software, version 4.2.

\section{Results}

\section{Characteristics of controls and patients}

Clinical characteristics and lipid parameters of AHT patients and controls are presented in Table 1. As expected, age, triglyceridemia (TG), LDL, total cholesterol (TC), Glycemia (Gly), CT/HDL ratio, Sbp and Dbp were significantly different between AHT patients and controls. In addition, HDL/LDL ratio was significantly elevated in controls. There was no significant difference in body mass index (BMI) and HDL between both groups.

\section{Genotype frequency and linkage disequilibrium}

The $-1131 \mathrm{~T}>\mathrm{C}, 56 \mathrm{C}>\mathrm{G}$ SNPs had a strong association with AHT in all genetic models, the p-values remained significant after Bonferroni correction. The c.553G > T polymorphism had a significant association with AHT in co-dominant and dominant models, but this association was lost after Bonferroni correction (Table 2).

To determine the extent of linkage disequilibrium (LD) among the three polymorphisms, standardized LD coefficient D' was calculated for all pairs of polymorphisms. Figure 1 shows that with the exception of $-1131 \mathrm{~T}>\mathrm{C}$ and $56 \mathrm{C}>\mathrm{G}$ polymorphisms which were in strong linkage disequilibrium $\left(D^{\prime}=50\right)$, other polymorphisms were not in linkage disequilibrium (Figure 1).

\section{Comparisons of clinical and biochemical parameters between APOA5 genotypes}

We compared biological and clinical traits between APOA5 genotypes under dominant model for all patients

Table 1 Clinical and biochemical characteristics of controls and patients with AHT

\begin{tabular}{cccc}
\hline & Controls $(\mathbf{n}=\mathbf{1 3 4})$ & Patients $(\mathbf{n}=\mathbf{1 4 9})$ & P-value \\
\hline Age (years) & $50.78 \pm 12.08$ & $59.76 \pm 11.65$ & $<0.0001$ \\
Sbp (mmgHg) & $121.69 \pm 6.77$ & $153.09 \pm 19.19$ & $<0.0001$ \\
Dbp (mmgHg) & $77.49 \pm 7.97$ & $85.97 \pm 10.91$ & $<0.0001$ \\
BMl (kg/m $\left.{ }^{2}\right)$ & $26.49 \pm 4.11$ & $27.42 \pm 4.63$ & 0.0739 \\
TG (g/L) & $0.98 \pm 0.31$ & $1.65 \pm 0.85$ & $<0.0001$ \\
LDL (g/L) & $1.15 \pm 0.28$ & $1.34 \pm 0.45$ & $<0.0001$ \\
HDL (g/L) & $0.51 \pm 0.13$ & $0.50 \pm 0.17$ & 0.5042 \\
Gly (g/L) & $0.91 \pm 0.14$ & $1.23 \pm 0.57$ & $<0.0001$ \\
TC (g/L) & $1.88 \pm 0.28$ & $2.12 \pm 0.51$ & $<0.0001$ \\
TC/HDL & $3.90 \pm 0.94$ & $4.64 \pm 1.61$ & $<0.0001$ \\
HDL/LDL & $0.48 \pm 0.24$ & $0.43 \pm 0.32$ & 0.0002 \\
\hline
\end{tabular}

BMI: bodymass index, TC: Serum total cholesterol, TG: Triglycerides, HDL: High-Density Lipoprotein Cholesterol, LDL: Low-density Lipoprotein Cholesterol, Sbp systolic blood pressure, Dbp diastolic blood pressure. and controls combined. The APOA5 -1131 T $>\mathrm{C}$ polymorphism was significantly associated with increased levels of systolic blood pressure, diastolic blood pressure and triglycerides (all $\mathrm{P}$ values $<0.0001$ ). We found significantly elevated systolic blood pressure $(\mathrm{P}=0.0001)$ and triglycerides levels $(\mathrm{P}<0.0001)$ in association with APOA5 56C $>$ G polymorphism. No Significant association was observed for APOA5 c.553G > T polymorphism (Table 3).

\section{APOA5 haplotype analysis}

To examine the combined effect of three variants (in the order of $-1131 \mathrm{~T}>\mathrm{C}, 56 \mathrm{C}>\mathrm{G}$ and c.553G $>\mathrm{T}$ polymorphisms of APOA5) in the APOA5 gene. There were 4 haplotypes identified in the APOA5gene in our population, with frequencies greater than 5\% (Table 4). Results of the logistic regression analysis suggested that the haplotype H1 (APOA $5 * 1$ ) has a protective effect against AHT. Two haplotypes confers significant susceptibility to AHT; haplotype $\mathrm{H} 2$ (APOA5*2) and haplotype $\mathrm{H} 4$. No significant association was observed between the haplotype $\mathrm{H} 3\left(\mathrm{APOA}^{*} 3\right)$ and AHT. The frequencies of the four haplotypes are listed in Table 4. Analysis of the interaction between haplotypes, Serum lipid parameters and environment factors showed that the H1 haplotype was associated with lower systolic blood pressure (SBP), diastolic blood pressure (DBP) and total plasma (TG). The H2 haplotype was significantly associated with increased SBP. Carriers of the H4 haplotype had a significant increased SBP, DBP and TG. No significant difference was detected between carriers and noncarriers of H3 haplotype. Age, BMI, LDL, HDL and glycemia were also analyzed but no significant difference was found in these parameters among the four haplotypes (Table 5).

\section{Discussion}

Many evidences were reported showing that apolipoprotein A1/C3/A4/A5 gene cluster is associated with premature coronary artery disease [10] and serum lipid levels [10]. Recent findings indicate that APOA5 could also influence cholesterol homeostasis and probably could play a role in hypertriglyceridemia associated with diabetes and inflammation [11].

The APOA5 polymorphisms were also identified to be implicated in regulation of blood pressure and in the development of hypertension in Japanese population [12].

Our data demonstrate that the $56 \mathrm{C}>\mathrm{G}$ SNP has a significant influence on blood pressure and triglyceride levels. This variant had not previously been investigated in Moroccan populations, although several different studies of other populations are available, supporting the importance of our study. The frequency 
Table 2 Genotypic distribution of APOA5 polymorphisms and statistic comparison between AHT subjects and controls

\begin{tabular}{|c|c|c|c|c|c|c|}
\hline SNP & Model & Controls & Patients & OR $(95 \% \mathrm{Cl})$ & $\mathbf{P}$ & Pc \\
\hline \multicolumn{7}{|c|}{$-1131 \mathrm{~T}>\mathrm{C}$} \\
\hline & \multicolumn{6}{|l|}{ Codominant } \\
\hline & $\pi$ & $128(95.5 \%)$ & 97 (65.1\%) & 1.00 & & \\
\hline & $\mathrm{TC}$ & $2(1.5 \%)$ & 20 (13.4\%) & $11.16(2.46-50.69)$ & 0.002 & $0.006^{*}$ \\
\hline & $\mathrm{CC}$ & $4(3 \%)$ & $32(21.5 \%)$ & $14.20(4.50-44.77)$ & $<0.0001$ & $<0.0001^{*}$ \\
\hline & \multicolumn{6}{|l|}{ Dominant } \\
\hline & $\pi$ & $128(95.5 \%)$ & 97 (65.1\%) & 1.00 & & \\
\hline & $\mathrm{TC} / \mathrm{CC}$ & $6(4.5 \%)$ & 52 (34.9\%) & $13.20(5.14-33.91)$ & $<0.0001$ & $<0.0001^{*}$ \\
\hline & \multicolumn{6}{|l|}{ Recessive } \\
\hline & TT/TC & 130 (97\%) & $117(78.5 \%)$ & 1.00 & & \\
\hline & $\mathrm{CC}$ & $4(3 \%)$ & $32(21.5 \%)$ & $12.35(3.91-39.05)$ & $<0.0001$ & $<0.0001^{*}$ \\
\hline \multicolumn{7}{|c|}{$56 C>G$} \\
\hline & \multicolumn{6}{|l|}{ Codominant } \\
\hline & CC & $117(87.3 \%)$ & $106(71.1 \%)$ & 1.00 & & \\
\hline & CG & $15(11.2 \%)$ & $21(14.1 \%)$ & $1.54(0.72-3.29)$ & 0.269 & NS \\
\hline & GG & $2(1.5 \%)$ & $22(14.8 \%)$ & $13.75(3.01-62.75)$ & 0.001 & $0.003^{*}$ \\
\hline & \multicolumn{6}{|l|}{ Dominant } \\
\hline & CC & $117(87.3 \%)$ & $106(71.1 \%)$ & 1.00 & & \\
\hline & $\mathrm{CG} / \mathrm{GG}$ & $17(12.7 \%)$ & $43(28.9 \%)$ & $2.90(1.49-5.63)$ & 0.002 & $0.006^{*}$ \\
\hline & Recessive & & & & & \\
\hline & $\mathrm{CC} / \mathrm{CG}$ & $132(98.5 \%)$ & $127(85.2 \%)$ & 1.00 & & \\
\hline & GG & $2(1.5 \%)$ & $22(14.8 \%)$ & $12.77(2.82-57.73)$ & 0.001 & $0.003^{*}$ \\
\hline \multicolumn{7}{|c|}{ c. $553 \mathrm{G}>\mathrm{T}$} \\
\hline & \multicolumn{6}{|l|}{ Codominant } \\
\hline & GG & 130 (97\%) & $132(88.6 \%)$ & 1.00 & & \\
\hline & GT & $3(2.2 \%)$ & 15 (10.1\%) & $4.72(1.28-17.35)$ & 0.020 & NS \\
\hline & $\Pi$ & $1(0.8 \%)$ & $2(1.3 \%)$ & $1.64(0.14-19.78)$ & 0.695 & NS \\
\hline & \multicolumn{6}{|l|}{ Dominant } \\
\hline & GG & 130 (97\%) & $132(88.6 \%)$ & 1.00 & & \\
\hline & $\mathrm{GT} / \mathrm{TT}$ & $4(3 \%)$ & 17 (11.4\%) & $3.92(1.23-12.43)$ & 0.02 & NS \\
\hline & \multicolumn{6}{|l|}{ Recessive } \\
\hline & GG/GT & $133(99.2 \%)$ & 147 (98.7\%) & 1.00 & & \\
\hline & $\pi$ & $1(0.8 \%)$ & $2(1.3 \%)$ & $1.47(0.12-17.70)$ & 0.763 & NS \\
\hline
\end{tabular}

NS: Not Significant.

Pc: P value corrected for multiple comparisons (Bonferroni correction).

*P values remains significant after Bonferroni correction.

of the $56 \mathrm{G}$ rare allele detected in Moroccan patients $(22 \%)$ is higher than that of European populations. Indeed, studies carried out with North Americans and Europeans found that the $56 \mathrm{G}$ allele frequency is around 6\% [6,7,13], whereas its frequency in North Americans of Hispanic ancestry is around 15\% [14]. Ruiz- Narváez registered a value of $10.2 \%$ for the 56G allele in Costa Rica, while other populations exhibited lower frequencies in the same study (Caucasians
$6 \%$, African-Americans 7\%) [15]. In addition to these studies, in 2003, Lai et al. investigated the frequency of the same polymorphism in people resident in Singapore [8]. The Chinese, Malay and Indian populations living in this region exhibited extremely low frequencies of the $56 \mathrm{G}$ polymorphism $(0.1 \%, 1 \%$ and $3 \%$, respectively). The $56 \mathrm{G}$ allele frequency varies between $0.1 \%$ in a Chinese population [8] and $15.8 \%$ in Hispanic males [16]. 


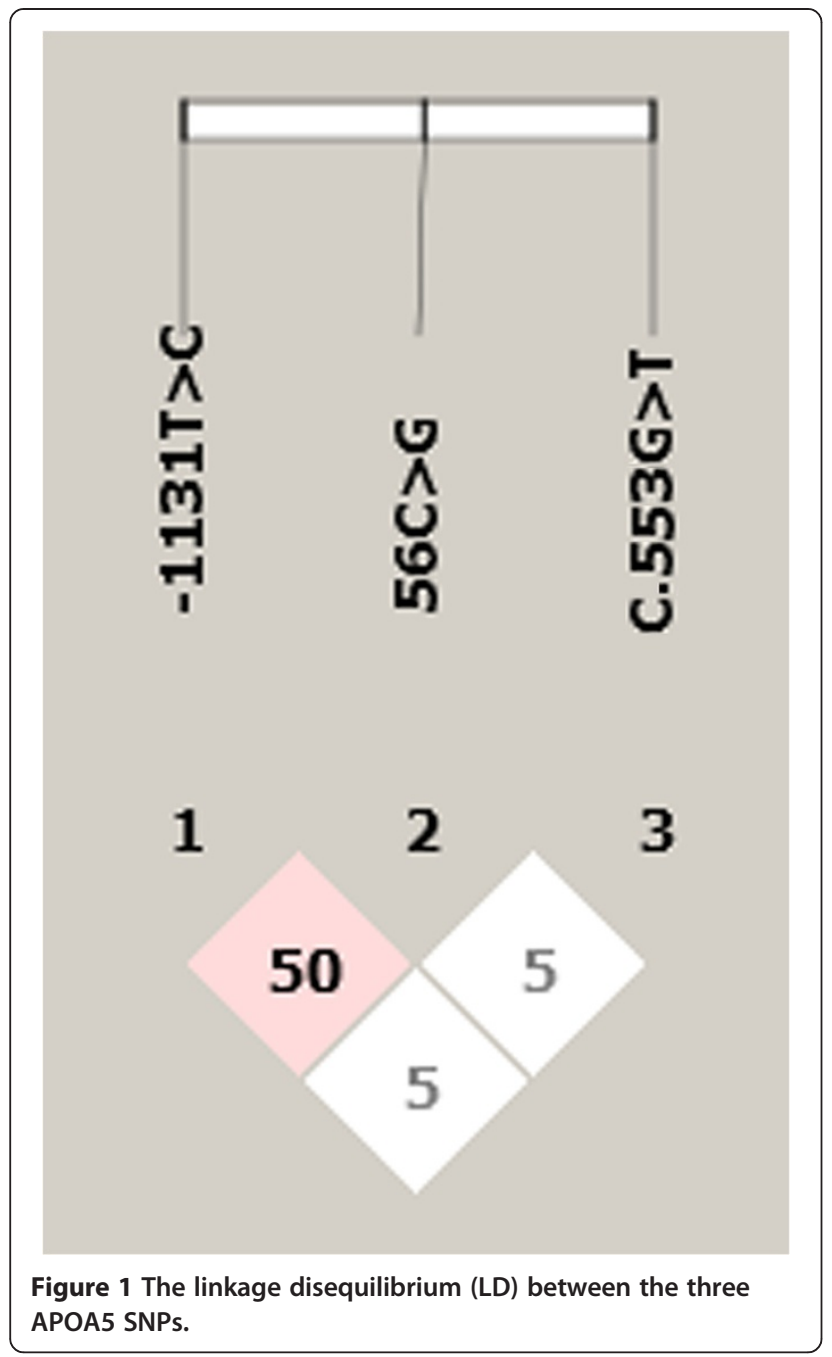

APOA5 gene codes for an apolipoprotein involved in the regulation of LPL activity $[17,18]$. ApoAV protein could facilitate the interaction between TG rich lipoproteins and proteoglycan-bound LPL. Transgenic mice models also suggested that apoAV might inhibit VLDL hepatic production but these findings were not confirmed in lipoprotein kinetic studies [19].

Although the association of $56 \mathrm{C}>\mathrm{G}$ polymorphism with lipid profile was already shown in various healthy populations [20], their impact on AHT dyslipidemia remains undocumented. In another study, this polymorphism was associated with higher TG and lower HDLc in diabetic patients, but only for Indian-Asian carriers [21]. There was no report of the impact of this polymorphism on history of dyslipidemia in AHT. Nevertheless, an increased 56G allele frequency was previously reported in non diabetic patients with severe hypertriglyceridemia [22,23]. The association between the 56G allele and increased triglycerides has already been documented in other populations, such as the North American and Northern Irish populations $[24,25]$. The results of the present study confirm the relationship between $A P O A 556 \mathrm{C}>\mathrm{G}$ polymorphism and plasma triglycerides, as carriers of the $56 \mathrm{G}$ variant were associated strongly with triglyceride levels. In addition to elevated triglyceride levels, the APOA5 56G was associated with higher systolic blood pressure relative to $56 \mathrm{C}$ carriers. A direct effect of APOA5 on blood pressure regulation is unlikely. In contrast, there is experimental evidence to suggest that chronic hypertriglyceridemia leads to endothelium dysfunction, which is associated with an impaired response to vasodilator stimulation [26] and a subsequent decrease in nitric

Table 3 Association between APOA5 genotype variants and clinical and biochemical parameters

\begin{tabular}{|c|c|c|c|c|c|c|c|c|c|}
\hline & \multicolumn{3}{|c|}{ APOA5 -1131 T >C } & \multicolumn{3}{|l|}{ APOA5 56C > G } & \multicolumn{3}{|c|}{ APOA5 c.553G > T } \\
\hline & $\overline{\mathrm{TT}}$ & $\mathrm{TC}+\mathrm{CC}$ & P-value & $\overline{\mathrm{CC}}$ & $\mathrm{CG}+\mathrm{GG}$ & P-value & $\overline{\mathrm{GG}}$ & $\mathrm{GT}+\mathrm{TT}$ & P-value \\
\hline Patient (number) & 97 & 52 & & 106 & 43 & & 132 & 17 & \\
\hline Controls (number) & 128 & 6 & & 117 & 17 & & 130 & 4 & \\
\hline Age (years) & $54.94 \pm 12.62$ & $57.72 \pm 12.68$ & 0.1353 & $55.13 \pm 12.62$ & $56.90 \pm 12.82$ & 0.3386 & $55.24 \pm 12.84$ & $58.81 \pm 9.87$ & 0.215 \\
\hline $\mathrm{Sbp}(\mathrm{mmgHg})$ & $133.67 \pm 19.71$ & $155.86 \pm 18.94$ & $<0.0001^{* *}$ & $135.32 \pm 20.27$ & $148.98 \pm 22.62$ & $0.0001^{* *}$ & $137.82 \pm 21.15$ & $143.24 \pm 25.40$ & 0.2495 \\
\hline $\mathrm{Dbp}(\mathrm{mmgHg})$ & $80.57 \pm 10.60$ & $87.33 \pm 8.24$ & $<0.0001^{* *}$ & $81.27 \pm 9.43$ & $84.48 \pm 13.59$ & $0.0355^{*}$ & $82.13 \pm 10.33$ & $79.81 \pm 12.60$ & 0.3319 \\
\hline $\mathrm{BMI}\left(\mathrm{kg} / \mathrm{m}^{2}\right)$ & $26.82 \pm 4.21$ & $27.58 \pm 5.11$ & 0.2428 & $26.79 \pm 4.21$ & $27.68 \pm 5.06$ & 0.1676 & $27.09 \pm 4.41$ & $25.63 \pm 4.30$ & 0.1446 \\
\hline $\mathrm{TG}(\mathrm{g} / \mathrm{L})$ & $1.23 \pm 0.63$ & $1.76 \pm 0.93$ & $<0.0001^{* *}$ & $1.23 \pm 0.64$ & $1.75 \pm 0.91$ & $<0.0001^{* *}$ & $1.32 \pm 0.74$ & $1.53 \pm 0.65$ & 0.0564 \\
\hline LDL (g/L) & $1.22 \pm 0.37$ & $1.37 \pm 0.44$ & $0.0101 *$ & $1.24 \pm 0.38$ & $1.31 \pm 0.43$ & 0.1889 & $1.25 \pm 0.39$ & $1.30 \pm 0.43$ & 0.5751 \\
\hline $\mathrm{HDL}(\mathrm{g} / \mathrm{L})$ & $0.51 \pm 0.17$ & $0.47 \pm 0.11$ & 0.0631 & $0.51 \pm 0.16$ & $0.47 \pm 0.12$ & 0.0746 & $0.50 \pm 0.16$ & $0.53 \pm 0.16$ & 0.3976 \\
\hline Gly (g/L) & $1.06 \pm 0.46$ & $1.13 \pm 0.43$ & 0.0582 & $1.09 \pm 0.48$ & $1.04 \pm 0.29$ & 0.9913 & $1.06 \pm 0.43$ & $1.33 \pm 0.65$ & 0.0668 \\
\hline $\mathrm{TC}(\mathrm{g} / \mathrm{L})$ & $1.97 \pm 0.41$ & $2.15 \pm 0.52$ & $0.0045^{*}$ & $1.98 \pm 0.41$ & $2.10 \pm 0.51$ & 0.0627 & $2.00 \pm 0.44$ & $2.13 \pm 0.42$ & 0.1688 \\
\hline
\end{tabular}

*P values not significant after Bonferroni correction.

**P values remains significant after Bonferroni correction. 
Table 4 Association analysis of haplotypes derived from polymorphic sites using genotype data

\begin{tabular}{|c|c|c|c|c|c|c|c|c|}
\hline \multirow[t]{2}{*}{ Haplotype } & \multirow[t]{2}{*}{$-1131 \mathrm{~T}>\mathrm{C}$} & \multirow[t]{2}{*}{$56 C>G$} & \multirow[t]{2}{*}{ c.553G > T } & \multicolumn{2}{|c|}{ Frequency } & \multirow[t]{2}{*}{ OR $(95 \% \mathrm{Cl})$} & \multirow[t]{2}{*}{$P$} & \multirow[t]{2}{*}{ Pc } \\
\hline & & & & Controls & Cases & & & \\
\hline $\mathrm{H} 1$ & $\mathrm{~T}$ & C & G & 0.8970 & 0.6543 & $0.338(0.226-0.504)$ & $<0.0001$ & $<0.0001$ \\
\hline $\mathrm{H} 2$ & C & C & G & 0.0307 & 0.1307 & $3.07(1.49-6.31)$ & 0.0005 & 0.002 \\
\hline $\mathrm{H} 3$ & $\mathrm{~T}$ & G & G & 0.0649 & 0.0625 & $0.809(0.395-1.66)$ & 0.563 & NS \\
\hline $\mathrm{H} 4$ & C & G & G & 0.0073 & 0.1525 & $12.46(2.93-53)$ & $<0.0001$ & $<0.0001$ \\
\hline
\end{tabular}

NS: Not Significant.

Pc: P value corrected for multiple comparisons (Bonferroni correction).

oxide availability phenomena, which may result in increased blood pressure.

We found a significant difference between patients with AHT and controls regarding the frequency of $56 \mathrm{C}>\mathrm{G}$ and $-1131 \mathrm{~T}>\mathrm{C}$ genotypes in the additive, dominant and recessive models.

Several studies demonstrated that the presence of polymorphisms in the A1-C3-A4 cluster and other gene loci determines the variability of the postprandial lipoprotein response $[27,28]$. Recently a gene coding for $A P O A 5$ was identified in this cluster, and this is emerging as a main candidate gene for modulating TG metabolism in humans [6]. Two polymorphisms,$1131 \mathrm{~T}>\mathrm{C}$ and $56 \mathrm{C}>\mathrm{G}$, have been extensively studied and are independently associated with higher TG levels $[6,28,29]$. Previous studies have shown that plasma TG concentrations were $69 \%$ higher in CC subjects than TT subjects with the-1131 $\mathrm{T}>\mathrm{C}$ polymorphism $[8,30]$ and $20-30 \%$ higher in CG than CC subjects with the $56 \mathrm{C}>\mathrm{G}$ polymorphism [6,31]. Moreno et al. demonstrated that carriers of the $-1131 \mathrm{C}$ allele $(-1131 \mathrm{~T}>\mathrm{C})$ displayed a higher plasma TG concentration [32]. However, association studies using haplotypes should increase our ability to detect true associations and interactions.

The ApoA5 -1131C allele in our study population was similar to that in Chinese (29.9\%) [33-35], Singaporean (29.4\%) [8], Malays (30.0\%) [8], slightly lower than that in Japanese $(34.0 \%)$ [36,37], but much greater than that of whites (8.0\%) [5], Hispanic Americans (13.0\%-16.0\%) [6,38] or Tunisian (13.0\%) [39].The frequency of ApoA5 c.553G $>\mathrm{T}$ allele in this study is extremely low, and is in agreement with that of two previous studies in Chinese (3.97\%) [40] and Chinese Taiwanese (4.2-7.2\%) [41,42]. The ApoA5 c.553 T allele has been reported to be absent in Caucasians [43]. The ApoA5 c.553TT homozygous was similarly detected in our study population in agreement with a previous study [40].

To the best of our knowledge, this study is the first to determine that different haplotypes of APOA5 gene modulate the systolic, diastolic blood pressure and lipid levels in AHT patients. Thus, our data show markedly higher systolic and diastolic blood pressure in subjects with the APOA5 $\mathrm{H} 2$ and APOA5 $\mathrm{H} 4$ haplotypes, which may explain the higher risk of coronary heart disease associated with the $56 \mathrm{G}$ and $-1131 \mathrm{C}$ alleles [31,44].

In our study, both the APOA5 $\mathrm{H} 2$ and APOA5 $\mathrm{H} 4$ haplotypes were significantly associated with increase in systolic blood pressure. In addition the $\mathrm{H} 4$ haplotype was associated with higher DBP and TG levels. In contrast the $\mathrm{H} 1$ haplotype showed significant association with lower SBP, DBP and total plasma TG. These results suggest that each of these haplotypes may be associated with different mechanisms that enhance the plasma lipid levels and the risk of atherogenesis.

All these data suggested the importance of $A P O A 5$ in the regulation of plasma triglyceride concentrations. Furthermore, pair wise linkage disequilibrium comparison performed in this study between APOA5 $-1131 \mathrm{~T}<\mathrm{C}$ and $A P O A 556 \mathrm{C}>\mathrm{G}$ demonstrated that they are linked, suggesting cooperation mechanisms for the associations with plasma lipoproteins and related traits. Metabolic syndrome (MetS) is a cluster of disorders which includes visceral obesity, dyslipidaemia, hyperglycaemia, and hypertension [45]. The association of APOA5 polymorphisms with increased risk of metabolic syndrome was showed in several studies [46]. The APOA5 gene plays an important role in regulating triglyceride levels. This regulation may contribute to the association between APOA5 and hypertension showed in this paper, but we cannot exclude other mechanisms.

Our study has same limitations; waist conference wasn't measured to assess central obesity. In addition, the APOA5 - $1131 \mathrm{~T}>\mathrm{C}$ and c.553G $>\mathrm{T}$ polymorphisms were not in Hardy-Weinberg equilibrium.

In summary, we demonstrated that common variants of APOA5 gene are associated with AHT and contribute to the variation in human plasma TG. Therefore, APOA5 variant was a significant predictor for high triglyceride risk and the APOA5 haplotypes affected dyslipidemia appreciably among the Moroccan population.

\section{Conclusion}

In conclusion, we demonstrate for the first time that APOA5 polymorphisms and haplotypes have a strong 
Table 5 Association between APOA5 haplotypes and clinical and biochemical parameters

\begin{tabular}{|c|c|c|c|c|c|c|c|c|c|c|c|c|}
\hline & \multicolumn{3}{|c|}{ Haplotype H1 (TCG) } & \multicolumn{3}{|c|}{ Haplotype H2 (CCG) } & \multicolumn{3}{|c|}{ Haplotype H3 (TGG) } & \multicolumn{3}{|c|}{ Haplotype H4 (CGG) } \\
\hline & Present & $\begin{array}{l}\text { Not } \\
\text { present }\end{array}$ & $P$ value & Present & $\begin{array}{l}\text { Not } \\
\text { present }\end{array}$ & $P$ value & Present & $\begin{array}{l}\text { Not } \\
\text { present }\end{array}$ & $P$ value & Present & $\begin{array}{l}\text { Not } \\
\text { present }\end{array}$ & $P$ value \\
\hline Age (years) & $55.10 \pm 12.36$ & $57.52 \pm 14.00$ & 0.2276 & $56.97 \pm 13.12$ & $55.33 \pm 12.62$ & 0.4976 & $57.03 \pm 14.38$ & $55.33 \pm 12.46$ & 0.4865 & $57.50 \pm 12.69$ & $55.25 \pm 12.66$ & 0.3458 \\
\hline $\mathrm{Sbp}(\mathrm{mmgHg})$ & $134.79 \pm 19.84$ & $155.00 \pm 21.55$ & $<0.0001^{* *}$ & $152.55 \pm 17.19$ & $136.46 \pm 21.33$ & $<0.0001^{* *}$ & $139.10 \pm 21.19$ & $138.11 \pm 21.56$ & 0.7795 & $157.56 \pm 21.21$ & $135.75 \pm 20.27$ & $<0.0001^{* *}$ \\
\hline $\mathrm{Dbp}(\mathrm{mmgHg})$ & $81.03 \pm 10.41$ & $86.48 \pm 9.88$ & $0.001^{* *}$ & $86.35 \pm 8.47$ & $81.41 \pm 10.62$ & $0.0132^{*}$ & $81.40 \pm 16.88$ & $82.02 \pm 9.52$ & 0.7606 & $87.88 \pm 8.59$ & $81.20 \pm 10.50$ & $0.0006^{* *}$ \\
\hline BMI (kg/m2) & $26.85 \pm 4.30$ & $27.64 \pm 4.90$ & 0.2596 & $26.50 \pm 4.67$ & $27.04 \pm 4.38$ & 0.5181 & $27.11 \pm 4.88$ & $26.97 \pm 4.36$ & 0.8684 & $28.12 \pm 5.56$ & $26.83 \pm 4.23$ & 0.1195 \\
\hline $\mathrm{TG}(\mathrm{g} / \mathrm{L})$ & $1.24 \pm 0.65$ & $1.81 \pm 0.92$ & $<0.0001^{* *}$ & $1.38 \pm 0.69$ & $1.33 \pm 0.74$ & 0.497 & $1.61 \pm 1.00$ & $1.31 \pm 0.69$ & 0.1055 & $1.99 \pm 0.98$ & $1.25 \pm 0.65$ & $<0.0001^{* *}$ \\
\hline $\operatorname{LDL}(\mathrm{g} / \mathrm{L})$ & $1.23 \pm 0.37$ & $1.36 \pm 0.47$ & $0.0402^{*}$ & $1.42 \pm 0.46$ & $1.23 \pm 0.38$ & $0.0107^{*}$ & $1.24 \pm 0.43$ & $1.25 \pm 0.39$ & 0.8132 & $1.36 \pm 0.45$ & $1.24 \pm 0.38$ & 0.0883 \\
\hline $\mathrm{HDL}(\mathrm{g} / \mathrm{L})$ & $0.51 \pm 0.16$ & $0.45 \pm 0.10$ & $0.0061 *$ & $0.48 \pm 0.10$ & $0.50 \pm 0.16$ & 0.4389 & $0.47 \pm 0.14$ & $0.51 \pm 0.16$ & 0.2057 & $0.47 \pm 0.12$ & $0.51 \pm 0.16$ & 0.1585 \\
\hline Gly (g/L) & $1.07 \pm 0.46$ & $1.12 \pm 0.39$ & 0.2406 & $1.16 \pm 0.49$ & $1.07 \pm 0.44$ & 0.1619 & $0.99 \pm 0.21$ & $1.09 \pm 0.47$ & 0.6938 & $1.08 \pm 0.33$ & $1.08 \pm 0.46$ & 0.5571 \\
\hline TC (g/L) & $1.98 \pm 0.41$ & $2.15 \pm 0.54$ & $0.0122^{*}$ & $2.15 \pm 0.53$ & $1.99 \pm 0.42$ & 0.0604 & $2.00 \pm 0.48$ & $2.01 \pm 0.43$ & 0.8825 & $2.18 \pm 0.54$ & $1.98 \pm 0.42$ & $0.0162^{*}$ \\
\hline
\end{tabular}

*P values not significant after Bonferroni correction.

**P values remains significant after Bonferroni correction. 
influence on systolic and diastolic blood pressures and triglyceride levels in Moroccan patients with AHT. Our results showed that APOA5 56C $>\mathrm{G}$ and $-1131 \mathrm{~T}>\mathrm{C}$ polymorphisms play a major role in elevated risk of developing coronary artery disease due to its association with increased plasma TG.

\section{Competing interests}

The authors declare that they have no competing interests.

\section{Authors' contributions}

AB conceived, designed and coordinated the study. SO, MA and HS performed the laboratory work. $\mathrm{HC}$ and $\mathrm{HB}$ carried out statistical analysis. SO, $\mathrm{HC}$ and $\mathrm{HB}$ wrote the paper. NG, HRh, HRo participated in statistical analyses and interpretation of results. All authors read and approved the final manuscript.

\section{Acknowledgments}

We thank all families for their cooperation. The authors would also like to thank Dr. Guy Lenaers for his contribution to this work. This work was supported by a grant from the European Commission FP7 Integrated Project MEDIGENE (FP7-279171-1).

\section{Author details}

'Laboratoire de Génétique Moléculaire et Humaine, Département de Recherche Scientifique, Institut Pasteur du Maroc, 1, Place Louis Pasteur, 20360 Casablanca, Morocco. ${ }^{2}$ Laboratoire de Biochimie, Centre de Biologie Médicale, Institut Pasteur du Maroc, 1, Place Louis Pasteur, 20360 Casablanca, Morocco. 'Laboratoire de Physiologie et Génétique Moléculaire, Faculté des sciences Ben M'Sik, Université Hassan II, Mohammedia, Morocco.

Received: 24 December 2013 Accepted: 26 March 2014

Published: 1 April 2014

\section{References}

1. Kearney PM, Whelton M, Reynolds K, Muntner P, Whelton PK, He J: Global burden of hypertension: analysisof worldwide data. The Lancet 2005, 365(9455):217-223.

2. Mohan V, Seedat YJ, Pradeepa R: The rising burden of diabetes and hypertension in Southeast Asian and African regions: need for effectives strategies for prevention and control in primary health care settings. Int J Hypertens 2013. Doi: 10.1155/2013/409083.

3. Forrester JS: Triglycerides: risk factor or fellow traveler? Curr Opin Cardiol 2001, 16(4):261-264.

4. Malloy MJ, Kane JP: A risk factor for atherosclerosis: triglyceride-rich lipoproteins. Adv Intern Med 2001, 47:111-136.

5. Pennacchio LA, Olivier M, Hubacek JA, Cohen JC, Cox DR, Fruchart JC, Krauss RM, Rubin EM: An apolipoprotein influencing triglycerides in humans and mice revealed by comparative sequencing. Science 2001, 294(5540):169-173.

6. Pennacchio LA, Olivier M, Hubacek JA, Krauss RM, Rubin EM, Cohen JC: Two independent apolipoprotein A5 haplotypes influence human plasma triglyceride levels. Hum Mol Genet 2002, 11(24):3031-3038.

7. Klos KL, Hamon S, Clark AG, Boerwinkle E, Liu K, Sing CF: APOA5 polymorphisms influence plasma triglycerides in young, healthy African Americans and whites of the CARDIA Study. J Lipid Res 2005, 46(3):564-571.

8. Lai CQ, Tai ES, Tan CE, Cutter J, Chew SK, Zhu YP, Adiconis X, Ordovas JM: The APOA5 locus is a strong determinant of plasma triglyceride concentrations across ethnic groups in Singapore. J Lipid Res 2003, 44(12):2365-2373.

9. Francés F, Corella D, Sorlí JV, Guillén M, González Jl, Portolés O: Validating a rapid method for detecting common polymorphisms in the APOA5 gene by melting curve analysis using LightTyper. Clin Chem 2005, 51(7):1279-1282.

10. Shanker J, Perumal G, Rao VS, Khadrinarasimhiah NB, John S, Hebbagodi S, Mukherjee M, Kakkar W: Genetic studies on the APOA1-C3-A5 gene cluster in Asian Indians with premature coronary artery disease. Lipids Health Dis 2008, 7:33.
11. Qi L, Liu S, Rifai N, Hunter D, Hu FB: Associations of the apolipoprotein A1/ C3/A4/A5 gene cluster with triglyceride and HDL cholesterol levels in women with type 2 diabetes. Atherosclerosis 2007, 192(1):204-210.

12. Yamada $\mathrm{Y}$, Ando F, Shimokata $\mathrm{H}$ : Association of the genetic variants of APOA5 and PRKCH with hypertension in community-dwelling Japanese individuals. Mol Med Rep 2008, 1(3):407-414.

13. Evans D, Seedorf U, Beil FU: Polymorphisms in the apolipoprotein A5 (APOA5) gene and type III hyperlipidemia. Clin Genet 2005, 68(4):369-372.

14. Chien KL, Chen MF, Hsu HC, Su TC, Chang WT, Lee CM, Lee YT: Genetic association study of APOA1/C3/A4/A5 gene cluster and haplotypes on triglyceride and $\mathrm{HDL}$ cholesterol in a community-based population. Clin Chim Acta 2008, 388(1-2):78-83.

15. Ruiz-Narváez EA, Yang Y, Nakanishi Y, Kirchdorfer J, Campos H: APOC3/A5 haplotypes, lipid levels, and risk of myocardial infarction in the Central Valley of Costa Rica. J Lipid Res 2005, 46(12):2605-2613.

16. Chandak GR, Ward KJ, Yajnik CS, Pandit AN, Bavdekar A, Joglekar CV, Fall CH, Mohankrishna P, Wilkin TJ, Metcalf BS, Weedon MN, Frayling TM, Hattersley AT: Triglyceride associated polymorphisms of the APOA5 gene have very different allele frequencies in Pune. India compared to Europeans. BMC Med Genet 2006, 7:76.

17. Merkel M, Loeffler B, Kluger M, Fabig N, Geppert G, Pennacchio LA, Laatsch A, Heeren J: Apolipoprotein AV accelerates plasma hydrolysis of triglyceride-rich lipoproteins by interaction with proteoglycan-bound lipoprotein lipase. J Biol Chem 2005, 280(22):21553-21560.

18. Marçais $C$, Verges $B$, Charrière $S$, Pruneta V, Merlin M, Billon S, Perrot L, Drai J, Sassolas A, Pennacchio LA, Fruchart-Najib J, Fruchart JC, Durlach V, Moulin P: Apoa5 Q139X truncation predisposes to late-onset hyperchylomicronemia due to lipoprotein lipase impairment. J Clin Invest 2005, 115(10):2862-2869.

19. Chan DC, Watts GF, Nguyen MN, Barrett PH: Apolipoproteins C-III and $\mathrm{A}-\mathrm{V}$ as predictors of very-low-density lipoprotein triglyceride and apolipoprotein B-100 kinetics. Arterioscler Thromb Vasc Biol 2006, 26(3):590-596

20. Olivier M, Wang X, Cole R, Gau B, Kim J, Rubin EM, Pennacchio LA: Haplotype analysis of the apolipoprotein gene cluster on human chromosome 11. Genomics 2004, 83(5):912-923.

21. Dorfmeister B, Cooper JA, Stephens JW, Ireland H, Hurel SJ, Humphries SE, Talmud PJ: The effect of APOA5 and APOC3 variants on lipid parameters in European Whites, Indian Asians and Afro-Caribbeans with type 2 diabetes. Biochim Biophys Acta 2007, 1772(3):355-363.

22. Henneman P, Schaap FG, Havekes LM, Rensen PC, Frants RR, van Tol A Hattori H, Smelt AH, van Dijk KW: Plasma apoAV levels are markedly elevated in severe hypertriglyceridemia and positively correlated with the APOA5 S19W polymorphism. Atherosclerosis 2007, 193(1):129-134.

23. Wang J, Cao H, Ban MR, Kennedy BA, Zhu S, Anand S, Yusuf S, Pollex RL, Hegele RA: Resequencing genomic DNA of patients with severe hypertriglyceridemia (MIM 144650). Arterioscler Thromb Vasc Biol 2007, 27(11):2450-2455.

24. Lai CQ, Demissie S, Cupples LA, Zhu Y, Adiconis X, Parnell LD, Corella D, Ordovas JM: Influence of the APOA5 locus on plasma triglyceride, lipoprotein subclasses, and CVD risk in the Framingham Heart Study. J Lipid Res 2004, 45(11):2096-2105.

25. Wright WT, Young IS, Nicholls DP, Patterson C, Lyttle K, Graham CA: SNPs at the APOA5 gene account for the strong association with hypertriglyceridaemia at the APOA5/A4/C3/A1 locus on chromosome 11 q23 in the Northern Irish population. Atherosclerosis 2006, 185(2):353-360.

26. Kusterer $K$, Pohl T, Fortmeyer HP, März W, Scharnagl H, Oldenburg A, Angermüller S, Fleming I, Usadel KH, Busse R: Chronic selective hypertriglyceridemia impairs endothelium-dependent vasodilatation in rats. Cardiovasc Res 1999, 42(3):783-93.

27. Ordovas JM: Genetics, postprandial lipemia and obesity. Nutr Metab Cardiovasc Dis 2001, 11(2):118-133.

28. Martin S, Nicaud V, Humphries SE, Talmud PJ; EARS group: Contribution of APOA5 gene variants to plasma triglyceride determination and to the response to both fat and glucose tolerance challenges. Biochim Biophys Acta 2003, 1637(3):217-225.

29. Talmud PJ, Hawe E, Martin S, Olivier M, Miller GJ, Rubin EM, Pennacchio LA, Humphries SE: Relative contribution of variation within the APOC3/A4/A5 gene cluster in determining plasma triglycerides. Hum Mol Genet 2002, 11(24):3039-3046.

30. Lee KW, Ayyobi AF, Frohlich JJ, Hill JS: APOA5 gene polymorphism modulates levels of triglyceride, $\mathrm{HDL}$ cholesterol and FERHDL but is not a risk factor for coronary artery disease. Atherosclerosis 2004, 176(1):165-172. 
31. Talmud PJ, Martin S, Taskinen MR, Frick MH, Nieminen MS, Kesäniemi YA, Pasternack A, Humphries SE, Syvänne M: APOA5 gene variants, lipoprotein particle distribution, and progression of coronary heart disease: results from the LOCAT study. J Lipid Res 2004, 45(4):750-756.

32. Moreno R, Perez-Jimenez F, Marin C, Moreno JA, Gomez P, Bellido C, Perez-Martinez P, Jimenez-Gomez Y, Fuentes FJ, Lopez-Miranda J: A single nucleotide polymorphism of the apolipoprotein A-V gene -1131 $\mathrm{T}>\mathrm{C}$ modulates postprandial lipoprotein metabolism. Atherosclerosis 2006, 189(1):163-168.

33. Liu ZK, Hu M, Baum L, Thomas GN, Tomlinson B: Associations of polymorphisms in the apolipoprotein $\mathrm{A} 1 / \mathrm{C} 3 / \mathrm{A} 4 / \mathrm{A} 5$ gene cluster with familial combined hyperlipidaemia in Hong Kong Chinese. Atherosclerosis 2010, 208(2):427-432.

34. Baum L, Tomlinson B, Thomas GN: APOA5-1131 T >C polymorphism is associated with triglyceride levels in Chinese men. Clin Genet 2003, 63(5):377-379

35. Liu H, Zhang S, Lin J, Li H, Huang A, Xiao C, Li X, Su Z, Wang C, Nebert DW, Zhou B, Zheng K, Shi J, Li G, Huang D: Association between DNA variant sites in the apolipoprotein $\mathrm{A} 5$ gene and coronary heart disease in Chinese. Metabolism 2005, 54(5):568-572.

36. Endo K, Yanagi H, Araki J, Hirano C, Yamakawa-Kobayashi K, Tomura S: Association found between the promoter region polymorphism in the apolipoprotein $\mathrm{A}-\mathrm{V}$ gene and the serum triglyceride level in Japanese schoolchildren. Hum Genet 2002, 111(6):570-572.

37. Nabika T, Nasreen S, Kobayashi $\mathrm{S}$, Masuda J: The genetic effect of the apoprotein AV gene on the serum triglyceride level in Japanese. Atherosclerosis 2002, 165(2):201-204

38. Aouizerat BE, Kulkarni M, Heilbron D, Drown D, Raskin S, Pullinger CR, Malloy MJ, Kane JP: Genetic analysis of a polymorphism in the human apoA-V gene: effect on plasma lipids. J Lipid Res 2003, 44(6):1167-1173.

39. Chaaba R, Attia N, Hammami S, Smaoui M, Mahjoub S, Hammami M, Masmoudi AS: Association of SNP3 polymorphism in the apolipoprotein A-V gene with plasma triglyceride level in Tunisian type 2 diabetes. Lipids Health Dis 2005, 4:1.

40. Tang Y, Sun P, Guo D, Ferro A, Ji Y, Chen Q, Fan L: A genetic variant c.553G $>\mathrm{T}$ in the apolipoprotein $\mathrm{A} 5$ gene is associated with an increased risk of coronary artery disease and altered triglyceride levels in a Chinese population. Atherosclerosis 2006, 185(2):433-437.

41. Kao JT, Wen HC, Chien KL, Hsu HC, Lin SW: A novel genetic variant in the apolipoprotein $\mathrm{A} 5$ gene is associated with hypertriglyceridemia. Hum Mol Genet 2003, 12(19):2533-2539.

42. Hsu LA, Ko YL, Chang CJ, Hu CF, Wu S, Teng MS, Wang CL, Ho WJ, Ko YS, Hsu TS, Lee YS: Genetic variations of apolipoprotein A5 gene is associated with the risk of coronary artery disease among Chinese in Taiwan. Atherosclerosis 2006, 185(1):143-149.

43. Hubácek JA, Adámková V, Ceska R, Poledne R, Horínek A, Vráblík M: New variants in the apolipoprotein $\mathrm{AV}$ gene in individuals with extreme triglyceride levels. Physiol Res 2004, 53(2):225-228.

44. Dallongeville J, Cottel D, Montaye M, Codron V, Amouyel P, Helbecque N: Impact of APOA5/A4/C3 genetic polymorphisms on lipid variables and cardiovascular disease risk in French men. Int J Cardiol 2006, 106(2):152-156.

45. Alberti KG, Zimmet P, Shaw J: The metabolic syndrome-a new worldwide definition. Lancet 2005, 366(9491):1059-1062.

46. Povel CM1, Boer JM, Reiling E, Feskens EJ: Genetic variants and the metabolic syndrome: a systematic review. Obes Rev 2011, 12(11):952-967.

\section{Submit your next manuscript to BioMed Central and take full advantage of:}

- Convenient online submission

- Thorough peer review

- No space constraints or color figure charges

- Immediate publication on acceptance

- Inclusion in PubMed, CAS, Scopus and Google Scholar

- Research which is freely available for redistribution

Submit your manuscript at www.biomedcentral.com/submit 